\title{
Osmoregulated periplasmic glucans of Salmonella enterica serovar Typhimurium are required for optimal virulence in mice
}

\author{
Correspondence \\ Arvind A. Bhagwat \\ arvind.bhagwat@ars.usda.gov
}

Received 27 August 2008

Revised 23 September 2008

Accepted 29 September 2008
Arvind A. Bhagwat, ${ }^{1}$ Won Jun, ${ }^{1,4} \dagger$ Liu Liu, ${ }^{1,6} \S$ Porteen Kannan, ${ }^{1}$ Mahesh Dharne, ${ }^{1}$ Benedict Pheh, ${ }^{1} \|$ Ben D. Tall, ${ }^{3}$ Mahendra H. Kothary, ${ }^{3}$ Kenneth C. Gross, ${ }^{1}$ Scott Angle, ${ }^{5} \ddagger$ Jianghong Meng ${ }^{6}$ and Allen Smith ${ }^{2}$

\author{
${ }^{1}$ Produce Quality and Safety Laboratory, Henry A. Wallace Beltsville Agricultural Research Center \\ Agricultural Research Service, USDA, 10300 Baltimore Avenue, Bldg. 002, BARC-W, Beltsville, \\ MD 20705-235, USA \\ ${ }^{2}$ Diet Genomics and Immunology Laboratory, Henry A. Wallace Beltsville Agricultural Research \\ Center, Agricultural Research Service, USDA, 10300 Baltimore Avenue, Bldg. 002, BARC-W, \\ Beltsville, MD 20705-2350, USA \\ ${ }^{3}$ Food and Drug Administration, Division of Virulence Assessment, Laurel, MD 20708, USA \\ ${ }^{4}$ Department of Plant Science \& Landscape Architecture, University of Maryland, College Park, \\ MD 20742-7521, USA \\ ${ }^{5}$ College of Agriculture, University of Maryland, College Park, MD 20742-7521, USA \\ ${ }^{6}$ Department of Food Science and Nutrition, University of Maryland, College Park, \\ MD 20742-7521, USA
}

\begin{abstract}
We purified osmoregulated periplasmic glucans (OPGs) from Salmonella enterica serovar Typhimurium and found them to be composed of $100 \%$ glucose with 2-linked glucose as the most abundant residue, with terminal glucose, 2,3-linked and 2,6-linked glucose also present in high quantities. The two structural genes for OPG biosynthesis, opg $\mathrm{G}$ and opg $\mathrm{H}$, form a bicistronic operon, and insertion of a kanamycin resistance gene cassette into this operon resulted in a strain devoid of OPGs. The opg $\mathrm{GH}$ mutant strain was impaired in motility and growth under low osmolarity conditions. The opg $\mathrm{GH}$ mutation also resulted in a 2 log increase in the $\mathrm{LD}_{50}$ in mice compared to the wild-type strain SL1344. Inability to synthesize OPGs had no significant impact on the organism's lipopolysaccharide pattern or its ability to survive antimicrobial peptides-, detergent-, $\mathrm{pH}$ - and nutrient-stress conditions. We observed that the opg $\mathrm{GH}$-defective strain respired at a reduced rate under acidic growth conditions ( $\mathrm{pH}$ 5.0) and had lower ATP levels compared to the wild-type strain. These data indicate that OPGs of $S$. Typhimurium contribute towards mouse virulence as well as growth and motility under low osmolarity growth conditions.
\end{abstract}

tPresent address: Food Safety Laboratory, USDA-ARS, Beltsville, MD 20705, USA.

$\ddagger$ Present address: College of Agricultural and Environmental Sciences, University of Georgia, Athens, GA 30602, USA.

§Permanent address: North-west A\&F University, Yangling, PR China.

|lPermanent address: School of Life Sciences and Chemical Technology, Ngee Ann Polytechnic, Singapore 599489.

Abbreviation: OPG, osmoregulated periplasmic glucan.

Supplementary methods (describing stress-tolerance experiments and phenotypic microarray analysis), figures and tables are available with the online version of this paper.

\section{INTRODUCTION}

Osmoregulated periplasmic glucans (OPGs) are a heterogeneous group of soluble glucans primarily located in the periplasmic space of Gram-negative bacteria (Kennedy, 1996). In Escherichia coli, OPGs are composed of 8-10 glucose units per molecule in a highly branched structure, and the backbone is extensively substituted with $s n-1$ phosphoglycerol, phosphoethanolamine, and O-succinyl ester residues (Kennedy et al., 1976). OPGs of E. coli and the cyclic glucans of the Rhizobiaceae, as well as other Gram-negative plant pathogens, are localized in the periplasmic space, have glucose as a major constituent and in most cases their synthesis is osmotically regulated (Bohin \& Lacroix, 2007; Kennedy, 1996). 
OPGs have a critical biological function because mutants of E. coli deficient in OPG biosynthesis show altered chemotaxis and motility (Fiedler \& Rotering, 1988; Weissborn et al., 1992). OPGs have also been demonstrated to play a significant role in establishing successful pathogenic or symbiotic associations with plant hosts (Arellano-Reynoso et al., 2005; Bhagwat \& Keister, 1995; Page et al., 2001). Among animal pathogens, the role of OPGs has been examined in Brucella abortus (ArellanoReynoso et al., 2005), where synthesis of glucans is not osmoregulated (Briones et al., 1997). Despite the fact that the OPGs are postulated to play a significant role in many plant-pathogen interactions, the importance of OPGs in enteric human pathogens has not been studied (Coburn et al., 2005; Galan \& Cossart, 2005). To our knowledge, neither the structure nor function of Salmonella OPGs has been reported. In E. coli, genes for OPGs biosynthesis map to the opgGH operon and encode a glycosyltransferase $(\mathrm{OpgH})$ and $\mathrm{OpgG}$, a periplasmic protein presumed to be involved in polymerization of the OPG backbone (Bohin \& Lacroix, 2007; Hanoulle et al., 2004). Similar gene sequence homologues are found in the Salmonella genome (Parkhill et al., 2001). In this study, we mutated the opgGH operon of Salmonella enterica serovar Typhimurium SL1344. We also determined the glucosyl composition of wild-type OPGs and observed glucose to be the only constituent. Disruption of the opgGH operon resulted in a strain that lacked OPGs. The opgGH mutant had a longer lag period, reduced motility in hypoosmotic growth conditions and had attenuated virulence in mice.

\section{METHODS}

Bacterial strains and culture conditions. The strains used in this study (Table 1) were grown in Luria-Bertani (LB) medium at $37{ }^{\circ} \mathrm{C}$ in a shaking incubator at 220 r.p.m. When required, the medium was supplemented with antibiotics at the following concentrations: ampicillin $\left(100 \mu \mathrm{g} \mathrm{ml}^{-1}\right)$, kanamycin $\left(50 \mu \mathrm{g} \mathrm{ml}^{-1} ; \mathrm{Km}\right)$, nalidixic acid $\left(10 \mu \mathrm{g} \mathrm{ml}^{-1} ; \mathrm{Nal}\right)$, streptomycin $\left(50 \mu \mathrm{g} \mathrm{m}^{-1}\right.$; Sm). SalmonellaShigella agar and bismuth sulfite agar (Difco) Salmonella semiselective indicator media with appropriate antibiotics were used to isolate Salmonella from mouse tissue. Osmolarity of growth media was measured with a Wescor vapour pressure osmometer (model $5500)$.

The growth rates of wild-type and the opgGH mutant were determined in different growth media such as LB, LB with no salts (LBNS) and minimal E medium supplemented with $1.0 \%$ Casamino acids (osmolarity of $407 \pm 4,85 \pm 4$ and $310 \pm 9$ mosmol $^{-1}$, respectively) (Lin et al., 1995). LBNS broth diluted $1: 8$ in distilled water was used as low nutrient no salt (LNNS) medium ( $36 \pm 3$ mosmol $\left.1^{-1}\right)$. Growth was measured using a Bioscreen $\mathrm{C}$ automatic turbidometric analyser (GrowthCurves USA). Starter cultures were prepared by inoculating a single colony of the appropriate strain into LB followed by overnight incubation at $37^{\circ} \mathrm{C}$. This culture was diluted 1:10000 into fresh media of varying osmolarity and $250 \mu \mathrm{l}$ per well was transferred into a 100-well honeycomb Bioscreen plate. Growth was analysed at $37{ }^{\circ} \mathrm{C}$ with continuous shaking. To assess the effect of osmotic stress on growth, media were supplemented with varying amounts of salt $(\mathrm{NaCl}$ or $\mathrm{KCl})$ or buffered with HEPES (50 mM, pH 7.1). Swarming motility was determined $12 \mathrm{~h}$ after spot inoculation on media containing $0.35 \%$ Difco agar (Bhagwat et al., 1996; Chen et al., 2003) with varying amounts of $\mathrm{NaCl}[0-0.155 \mathrm{M}$ $\left(36 \pm 3-242 \pm 11 \mathrm{mosmol} \mathrm{l}^{-1}\right)$ ].

Statistical analysis. For statistical analyses, SigmaStat 3.0 software (Aspire Software International) was used. Data were analysed by a

Table 1. Bacterial strains and plasmids used in this study

\begin{tabular}{|c|c|c|}
\hline Strain or plasmid & Description & Reference \\
\hline \multicolumn{3}{|l|}{$S$. Typhimurium } \\
\hline S. Typhimurium & LT2 rpos' & SGSC $^{*}$ \\
\hline FIRN & Wild-type, $\mathrm{Nal}^{\mathrm{r}}$ & SGSC $^{*}$ \\
\hline FG111 & FIRN $o p g G H, \mathrm{Km}^{\mathrm{r}}$ & This study \\
\hline SL1344 & Wild-type, his $\mathrm{Sm}^{\mathrm{r}}$ & Hoiseth \& Stocker (1981) \\
\hline SG111 & SL1344 opgGH, $\mathrm{Km}^{\mathrm{r}}$ & This study \\
\hline \multicolumn{3}{|l|}{ E. coli } \\
\hline JM109 & $\begin{array}{l}\text { endA1 recA1 gyrA96 thi hsdR17 relA1 supE44 } \triangle\left(\text { lac-proAB) mcrA }\left(\mathrm{F}^{\prime} \text { traD36 proAB }\right.\right. \\
\left.\text { lacl }^{+} Z \Delta \mathrm{M} 15\right)\end{array}$ & Promega \\
\hline S17-1( $\lambda$ pir $)$ & recA thi pro $h s d R^{-} M^{+} R P 4: 2-T c: M u K m \operatorname{Tn} 7 \lambda$ pir, $\mathrm{Tp}^{\mathrm{r}}$ & Kim et al. (2002) \\
\hline \multicolumn{3}{|c|}{ 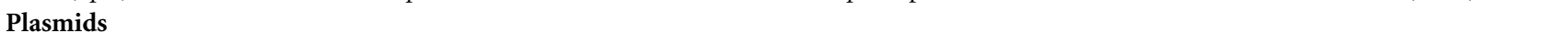 } \\
\hline pGEM-T & Vector for cloning of PCR products & Promega \\
\hline pUC4K & Source of the Km cassette & Stratagene \\
\hline pKNG101 & oriR6K mobRK2 sacB, suicide vector, $\mathrm{Sm}^{\mathrm{r}}$ & Kim et al. (2002) \\
\hline pOPGG1 & pGEM-T derivative harbouring 1924 bp opgG PCR fragment & This study \\
\hline pOPGG11 & $\begin{array}{l}882 \text { bp } H p a I-B s u 36 \text { I fragment containing the } o p g G \text { coding region from pOPGG1 } \\
\text { removed and replaced by Km cassette }\end{array}$ & This study \\
\hline pOPGG111 & $2.1 \mathrm{kbp}$ EcoRI fragment from pOPGG11 cloned into pKNG101 at SmaI site & This study \\
\hline pBP16 & $4.51 \mathrm{kbp}$ insert fragment flanking opgGH cloned into pGEM-T & This study \\
\hline pBK16 & $4.51 \mathrm{kbp}$ insert from pBP16 cloned into a low-copy-number vector (pPQSL2.0) & This study \\
\hline
\end{tabular}

*SGSC; Salmonella Genetic Stock Center, Alberta, Canada. 
one-way ANOVA test to determine statistical differences between means of treatments.

Construction of the opg GH mutant. $o p g G H$ is a bicistronic operon and the transcriptional start site of the opgH gene overlaps the Cterminal end of $o p g G$ by $7 \mathrm{nt}$ (www.ncbi.nlm.nih.gov/genomes/ lproks.cgi?view=1). The opgGH mutants of strain LT2 and FIRN were created in stepwise fashion. opgG with a 400 bp flanking region was amplified from LT2 genomic DNA using PCR primers OPGF1 (5'ACACCAACTCCGACAACCT- $3^{\prime}$ ) and OPGR1 (5'-CCCTTCGCCAATGAATC- $\left.3^{\prime}\right)$. The $1.9 \mathrm{kbp}$ amplified fragment was cloned into pGEM-T Easy vector (Promega), giving pOPGG1. The cloned opgG gene and the flanking region on pOPGG1 were confirmed by determining the DNA sequence in both orientations. An $882 \mathrm{bp}$ portion from the $o p g G$ structural gene (aa 13-306) from pOPGG1 was deleted using restriction endonucleases Bsu36I and HpaI, and replaced with the $1.1 \mathrm{kbp}$ kanamycin structural gene from pUC4K to yield pOPGG11. The insert was further cloned at an EcoRI site in pKNG101 to yield pOPGG111. pOPGG111 was mobilized to LT2 and FIRN by triparental mating (Bhagwat \& Keister, 1995). After sucrose selection (Kim et al., 2002), homologous recombinants $\left(\mathrm{Km}^{\mathrm{r}}\right.$ and $\mathrm{Sm}^{\mathrm{s}}$ ) were selected and confirmed by Southern blot hybridization (Fig. S1, available with the online version of this paper). The opgGH mutant strain of SL1344 was obtained by P22 transduction and confirmed by Southern blot analysis.

To clone the opgGH genes from S. Typhimurium SL1344 for complementation analysis, a $4.51 \mathrm{kbp}$ region, including $426 \mathrm{bp}$ upstream and 22 bp downstream, at the $o p g G H$ locus was amplified with forward primer G10 (5'-TTAAACAGGGTTAGCCACCA-3') and reverse primer C12 (5'-CTCACTCCAGACCTGAAGACC-3') using a Phusion Fidelity PCR kit (New England Biolabs), according to the manufacturer's instructions. The $4.51 \mathrm{kbp}$ fragment was cloned into pGEM-T to yield pBP16. The opgGH genes were cloned into a low-copy-number pACYC177-based vector (pPQSL_2.0) to obtain pBK16. pBK16 was mobilized into opgGH mutants by electroporation for complementation studies.

Large-scale isolation and purification of OPGs. To maximize the yield of OPGs, cells were grown in LBNS medium ( $85 \pm 4$ mosmol $\left.\mathrm{l}^{-1}\right)$, and OPGs were extracted by the charcoal adsorption procedure and eluted with aqueous pyridine as described by Lequette et al. (2004). After lyophilization, crude OPGs were subjected to gel filtration using a BioGel P-4 column $(1.5 \times 100 \mathrm{~cm})$. The column was eluted at room temperature with $7 \%$ 1-propanol, and OPG-containing fractions were monitored by determining the presence of hexose using the phenol/sulfuric acid assay (Dubois et al., 1956). The peak fractions containing the highest amounts of hexose were pooled and lyophilized to isolate total OPGs. The charged OPGs were further fractionated from total OPGs by ion-exchange chromatography using a DEAEcellulose (Whatman DE53; Sigma) column and eluted in a step-wise gradient from 0 to $0.5 \mathrm{M} \mathrm{NaCl}$. The unbound fraction was referred to as neutral OPGs, and the charged OPGs were eluted with $0.5 \mathrm{M} \mathrm{NaCl}$.

Glycosyl composition and glycosyl linkage methylation anaIysis. Glycosyl composition analysis was performed at the Complex Carbohydrate Research Center (Athens, GA, USA). Composition was determined by combined GC/MS of the per-O-trimethylsilyl derivatives of the monosaccharide methylglycosides produced from the samples by acidic methanolysis (Merkle \& Poppe, 1994; York et al., 1985). For glycosyl linkage analysis, the samples were permethylated, depolymerized, reduced and acetylated; and the resultant partially methylated alditol acetate samples were analysed by GC/MS (York et al., 1985).

Determination of succinate content from OPGs. Succinate content from OPGs were estimated as described earlier by Lacroix et al. (1999). Briefly, $1 \mathrm{mg}$ OPG was dissolved in $200 \mu \mathrm{l} 0.5 \mathrm{M} \mathrm{NaOH}$ and incubated at $100{ }^{\circ} \mathrm{C}$ for $30 \mathrm{~min}$ to liberate the succinyl residues from OPG. Glucosidic backbones were removed by adsorption on $50 \mathrm{mg}$ charcoal, and the charcoal was then washed three times with $0.5 \mathrm{ml}$ water. The four supernatants were pooled, lyophilized, dissolved in $200 \mu \mathrm{l}$ water and desalted on a minicolumn of Dowex AG50 $\times 8,20$ - to 50 -mesh $\left(\mathrm{H}^{+}\right.$form; Bio-Rad). After lyophilization, samples were dissolved in $1 \mathrm{ml}$ water, and succinic acid content was determined with a succinic acid kit (Roche R-Biopharma), according to the manufacturer's instructions.

Lipopolysaccharide analysis by PAGE. Bacterial cultures for analysis of LPS were grown overnight in LB at $37^{\circ} \mathrm{C}$, diluted $1: 100$ in the same medium and grown at $37{ }^{\circ} \mathrm{C}$ for $3 \mathrm{~h}$ to late-exponential phase. A $10 \mathrm{ml}$ sample was collected and centrifuged as described previously (Bhagwat et al., 1999; Johnson \& Perry, 1976). The cell pellet was resuspended in PBS to an $\mathrm{OD}_{600}$ of 0.5-0.6. The cell suspension $(1.5 \mathrm{ml})$ for LPS extraction was centrifuged and the pellet was resuspended in $50 \mu \mathrm{l}$ SDS-PAGE lysis buffer $(2 \%$ SDS, $4 \% 2$ mercaptoethanol, $10 \%$ glycerol, $0.002 \%$ Bromophenol Blue in $1 \mathrm{M}$ Tris/ $\mathrm{HCl}$ buffer, $\mathrm{pH}$ 6.8). Samples were incubated at $100{ }^{\circ} \mathrm{C}$ for $10 \mathrm{~min}$ and then cooled on ice for $5 \mathrm{~min}$. Samples were mixed with $25 \mu \mathrm{g}$ Proteinase $\mathrm{K}$, incubated for $1 \mathrm{~h}$ at $60{ }^{\circ} \mathrm{C}$, and then mixed with $50 \mu \mathrm{l} 90 \%$ phenol for $15 \mathrm{~min}$ at $70{ }^{\circ} \mathrm{C}$. Samples were centrifuged $(12500 \mathrm{~g}$ ) for $10 \mathrm{~min}$, and the aqueous phase was transferred to a new tube and extracted once with $500 \mu \mathrm{l}$ ethyl ether to remove traces of phenol. The upper ether phase was aspirated and the lower phase was mixed with an equal volume of SDS-PAGE lysis buffer. Ten microlitres of each sample was incubated at $100{ }^{\circ} \mathrm{C}$ for $5 \mathrm{~min}$, and then subjected to SDS-PAGE using a $15 \%$ acrylamide gel containing $4 \mathrm{M}$ urea (Sprott et al., 1994). LPS was visualized by silver staining (Tsai \& Frasch, 1982).

Mouse virulence studies. Five-week-old male BALB/c mice were purchased from the Small Animals Division of the National Cancer Institute (Frederick, MD, USA). Mice were housed in an AllenTown Caging Biocontainment isolator rack, 4-5 mice per cage, and provided with Harland-Teklad rodent chow and deionized water ad libitum. Mice were acclimated 1 week prior to use and all animal protocols were approved by the Institutional Animal Care and Use Committee. Animals were fasted for approximately $12 \mathrm{~h}$ prior to being inoculated with $0.2 \mathrm{ml}$ of an $S$. Typhimurium suspension (in $0.9 \% \mathrm{NaCl}$ ) by oral gavage. Bacterial strains were grown in $\mathrm{LB}$ medium at $37^{\circ} \mathrm{C}$ without shaking for $16-18 \mathrm{~h}$, suspended in saline and adjusted to an appropriate cell density before oral infection. Viable cell counts from individual oral dose dilutions were confirmed by retrospective spread-plating onto LB agar plates and incubating the plates for overnight at $37^{\circ} \mathrm{C}$.

To determine the effect of opgGH mutation on $S$. Typhimurium virulence, groups of mice (6-12 mice per group) were inoculated and monitored twice daily for signs of morbidity or mortality. Moribund mice were sacrificed and counted as dead. Survival curves were analysed using the Kaplan-Meier method with post hoc analysis for statistical significance. A value of $P<0.05$ was considered significant. Data from two experiments were combined and a probit model was fit to observed proportions surviving for each (strain, days, group) using SAS Proc PROBIT (SAS Institute, 1999) with the INVERSECL option to obtain $\mathrm{LD}_{50}$ estimates and confidence intervals (Finney, 1971; Hubert et al., 1988).

To analyse colonization of individual organs by each bacterial strain, mice were sacrificed 6 days post-infection. Individual organs (liver, spleen and entire intestine) were dissected, weighed and homogenized in LB. Cell counts were determined by spread-plating appropriate dilutions onto Brilliant green agar plates (Difco) containing streptomycin $\left(50 \mu \mathrm{g} \mathrm{ml}^{-1}\right)$ or $\mathrm{Km}\left(25 \mu \mathrm{g} \mathrm{m}^{-1}\right)$. Individual colonies were counted after overnight incubation at $37^{\circ} \mathrm{C}$ and statistical 
analysis was performed using ANOVA with post hoc analysis for multiple comparisons or the Mann-Whitney non-parametric test. A value of $P<0.05$ was considered significant.

Determination of cellular ATP contents. To determine the ATP content of cells during growth under acidic conditions, inoculum was prepared as described above for the Biolog $\mathrm{pH}$ panel, except that cells were inoculated in IF-10 media containing triethanolamine and glutaric acid (30 mM each, pH 5.0). Samples (100 $\mu$ l cell suspension) were withdrawn in triplicate at various times and mixed with $100 \mu \mathrm{l}$ luciferin-luciferase/lysis reagent (Promega), and the luminescent signal was measured after 5 min with a Berthold LB 9501 luminometer (Berthold Technologies).

\section{RESULTS}

\section{Isolation and characterization of OPGs}

OPGs from wild-type S. Typhimurium SL1344 were obtained as a single major peak of apparent molecular mass $\sim 1300$ Da from a BioGel P4 gel filtration column (Fig. 1a). No hexose-containing polymers eluted in the void volume. OPGs from SL1344 and from strains LT2 and FIRN had identical elution patterns (data not shown). The BioGel P4 elution pattern of OPG preparations from opgGH mutants was devoid of the corresponding peak (Fig. 1a). A significant proportion of the OPGs synthesized was anionic, with only $3 \%$ OPGs being neutral and did not bind to DEAE-cellulose (data not shown). Also, the succinic acid content of the OPG samples was estimated to be $0.95 \pm 0.23 \mu \mathrm{mol}(\mu \mathrm{mol} \mathrm{OPG})^{-1}$ (assuming 8 glucose residues per molecule of OPG). Total OPGs were further analysed for their hexosyl composition, and glucose was found to be the only component in $S$. Typhimurium strain SL1344 (Fig. 1c) as well as strains LT2 and FIRN (data not shown). Glycosyl linkage methylation analysis of OPGs from SL1344 indicated that 2-linked glucose was the most abundant residue, with terminal glucose, 2,3-linked and 2,6-linked glucose also present in high quantities (Fig. 1c). Synthesis of total OPGs [measured as $\mu$ g glucose equivalents $(\mathrm{mg} \text { cellular protein })^{-1}$ ] was influenced by the osmolarity of the external growth medium (Fig. 1b). Increasing growth medium osmolarity beyond 250 mosmol $1^{-1}$ adversely affected OPG synthesis. Practically no OPGs were synthesized at medium osmolarity levels greater than 440 mosmol $1^{-1}$.

\section{Growth and motility characteristics}

Growth rates of $o p g G H$ mutants in LB or LBNS broth, as well as in EG medium (see Supplementary Methods for a definition, available with the online version of this paper) with $1 \%$ Casamino acids (osmolarity levels of $407 \pm 4$, $85 \pm 4$ and $310 \pm 9$ mosmol $\mathrm{l}^{-1}$, respectively) were indistinguishable from wild-type parental strains (Fig. 2a; data not shown for EG medium). Compared to their growth (a)

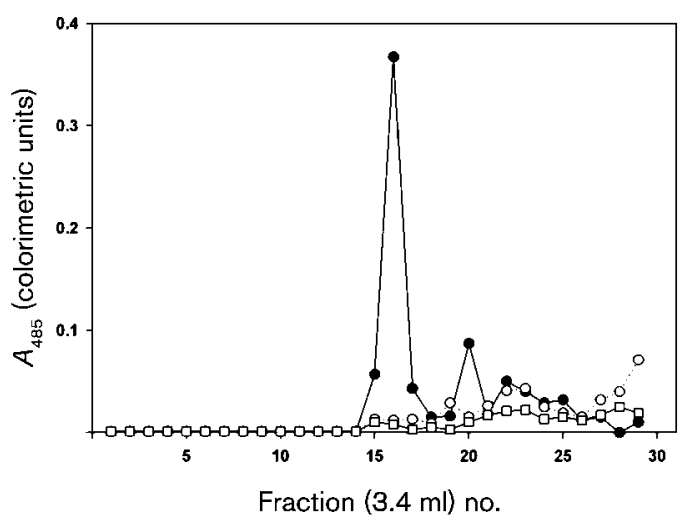

(b)

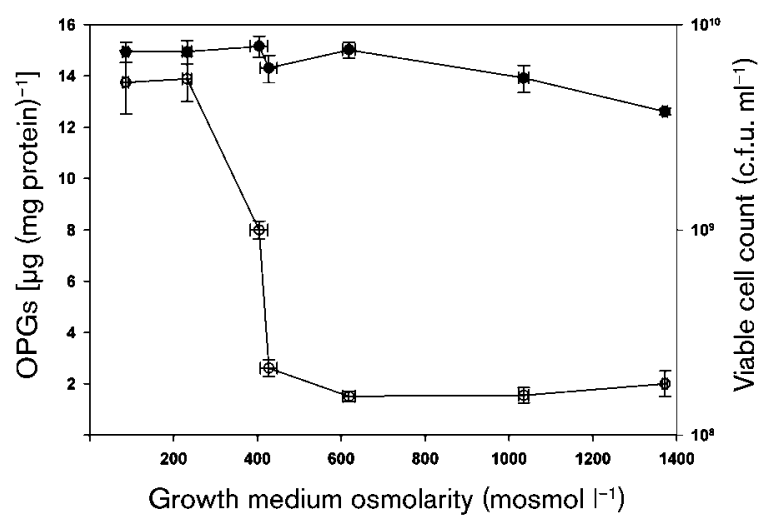

(c)

Glucose linkages (mol\%)

\begin{tabular}{cccccccc}
\hline $\mathrm{t}$ & -3 -linked & -2-linked & -6-linked & $-2,3$-linked & $-3,6$-linked & $-2,6$-linked & $-2,3,6$-linked \\
\hline $17.13 \pm 1.1$ & $4.27 \pm 1.7$ & $35.60 \pm 4.0$ & $4.80 \pm 1.6$ & $9.23 \pm 1.1$ & $1.37 \pm 1.0$ & $14.90 \pm 2.6$ & $3.40 \pm 2.9$ \\
\hline
\end{tabular}

Fig. 1. Characterization of OPGs from S. enterica serovar Typhimurium SL1344. (a) BioGel P4 gel filtration chromatography of OPGs from SL1344 (๑) and opgGH mutant strain SG111( $\square$ ). Crude OPGs obtained after pyridine extraction were lyophilized and fractionated using $7 \%$ 1-propanol on a BioGel P4 column $(1.5 \times 100 \mathrm{~cm})$. Fractions $(3.5 \mathrm{ml})$ were collected and analysed for total hexose by the phenol/sulfuric acid method. Cells were grown in LBNS [85 mosmol I ${ }^{-1} ;$ SL1344 (๑) and opgGH ( $\square$ )] or in LBNS + 0.5 M NaCl (1038 mosmol I ${ }^{-1}$; SL1344, $\left.\bigcirc\right)$. (b) Osmoregulation of OPGs. SL1344 cells were grown in LBNS with varying concentrations of $\mathrm{NaCl}\left(85-1370\right.$ mosmol I $\left.{ }^{-1}\right)$. OPGs obtained after BioGel P4 chromatography were estimated and plotted as $\mu \mathrm{g}$ OPGs (mg cellular protein $)^{-1}(\bigcirc)$. Viable cell count was determined by spread-plating serial 10-fold dilutions onto LB agar (@). (c) Linkage analysis of OPGs obtained after BioGel P4 chromatography. 

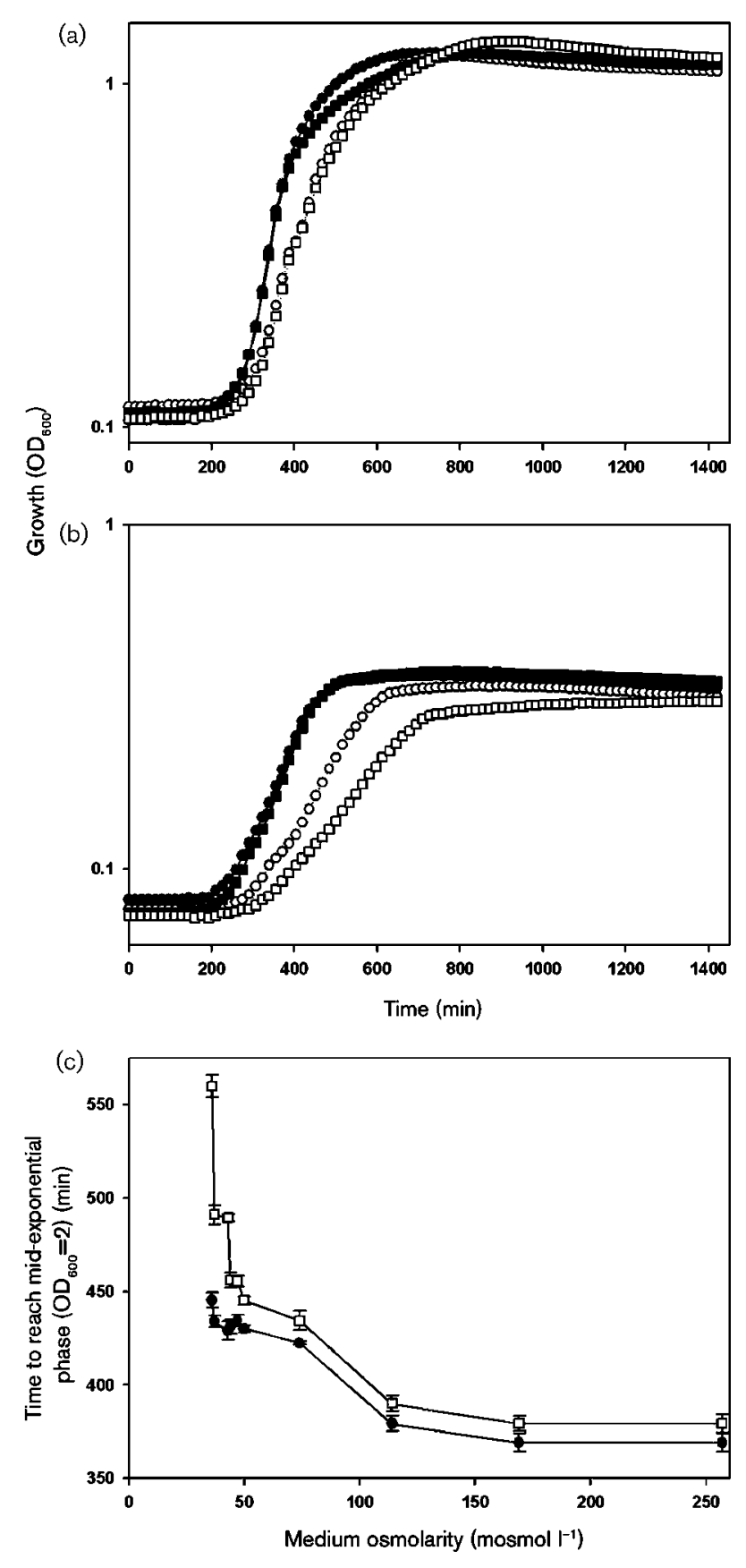

Fig. 2. Growth characteristics of wild-type (SL1344 $\bigcirc, 0)$ and the opg $\mathrm{GH}$ mutant strain $(\square, \boldsymbol{\square})$ in media with different osmolarities. (a) Growth curves in LBNS (84 mosmol I $; \bigcirc, \square$ ) and LB (407 mos$\left.\mathrm{mol} \mathrm{I}^{-1} ; \mathbf{0}, \mathbf{\square}\right)$ media. (b) Growth curves in LNNS (36 mosmol I-1; $\bigcirc, \square)$ and LNNS + $0.155 \mathrm{M} \mathrm{NaCl}\left(240\right.$ mosmol I$\left.^{-1} ; 0, \mathbf{0}\right)$. (c) Effect of medium osmolarity on time required to reach midexponential growth phase for SL1344 (O) and opgGH mutant strain SG111 ( $\square$ ). LNNS medium was supplemented with varying amounts of $\mathrm{NaCl}$ to adjust the osmolarity.

rates in LB broth $\left(407 \pm 4\right.$ mosmol $\left.1^{-1}\right)$, both SL1344 and SG111 strains were delayed by 89 and $85 \mathrm{~min}$, respectively, in entering mid-exponential growth phase (time to reach an $\mathrm{OD}_{600}$ of 0.6$)$ when grown in a lower osmolarity medium such as LBNS $\left(85 \pm 4\right.$ mosmol $\left.{ }^{-1}\right)$ (Fig. 2a, open versus closed symbols). With further reduction in medium osmolarity such as low-nutrient low-salt medium (LNNS, $36 \pm 3$ mosmol $^{-1}$; Fig. 2b), SG111 exhibited a much longer lag time in comparison with SL1344 (559 vs $445 \mathrm{~min}$, respectively). The lag period of SG111 was gradually reduced with increasing medium osmolarity by addition of either $\mathrm{NaCl}$ (Fig. 2c), $\mathrm{KCl}$ or HEPES buffer (data not shown).

Similarly, motility swarms of SG111 were significantly smaller in LNNS medium supplemented with $0.35 \%$ agar (Fig. 3), and this strain continued to exhibit reduced swarm motility even after adjusting the medium osmolarity up to 125 mosmol $1^{-1}$. There were no significant differences between SL1344 and SG111 in their swarm motility at osmolarity levels greater than $200 \mathrm{mosmol} \mathrm{l}^{-1}$. An opgGH mutant strain carrying pBK16 exhibited normal motility swarms, indistinguishable from the wild-type strain (Fig. 3), and also had identical growth characteristics as observed for the wild-type (data not shown).

\section{Mouse virulence studies}

To determine if the lack of OPGs had any influence on pathogenesis and virulence of Salmonella strains, mice were orally infected with $10^{6}$ cells per animal and mortality was monitored over the following 15 days (Fig. 4). The opgGH mutant strain exhibited reduced virulence compared to the wild-type strain and the opgGH mutant carrying complementing plasmid pBK16. In an independent study, we also performed mice inoculation experiments in which mice were given an oral dose in the range of $10^{3}-10^{7}$ cells per animal. The results of these experiments showed that $\log _{10} 4.7$ cells per animal were needed to achieve an $\mathrm{LD}_{50}$

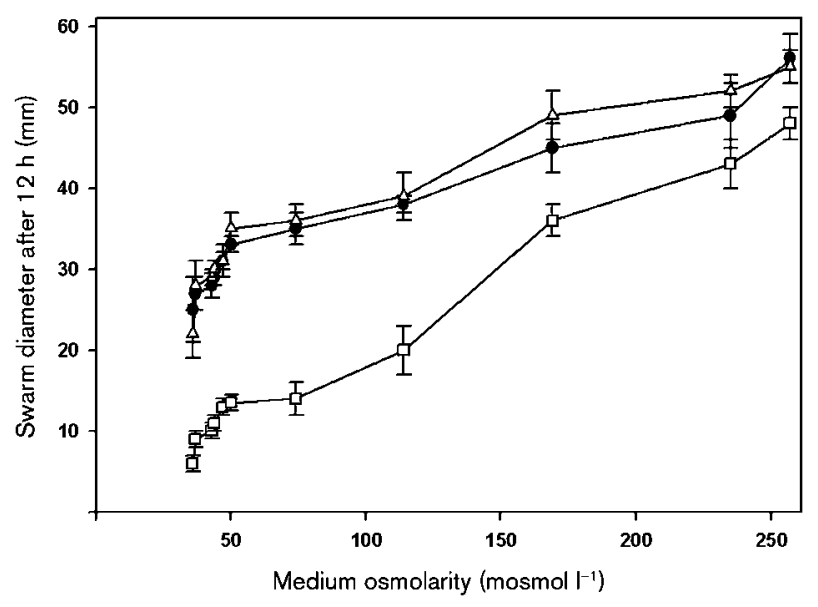

Fig. 3. Effect of the opgGH mutation on swarm motility. The graph shows swarm motility diameters (mm) of SL1344 (•), opg GH ( $\square$ ) and $o p g G H(\mathrm{pBK} 16)(\triangle) 12 \mathrm{~h}$ after inoculation in LNNS medium with varying osmolarity. 


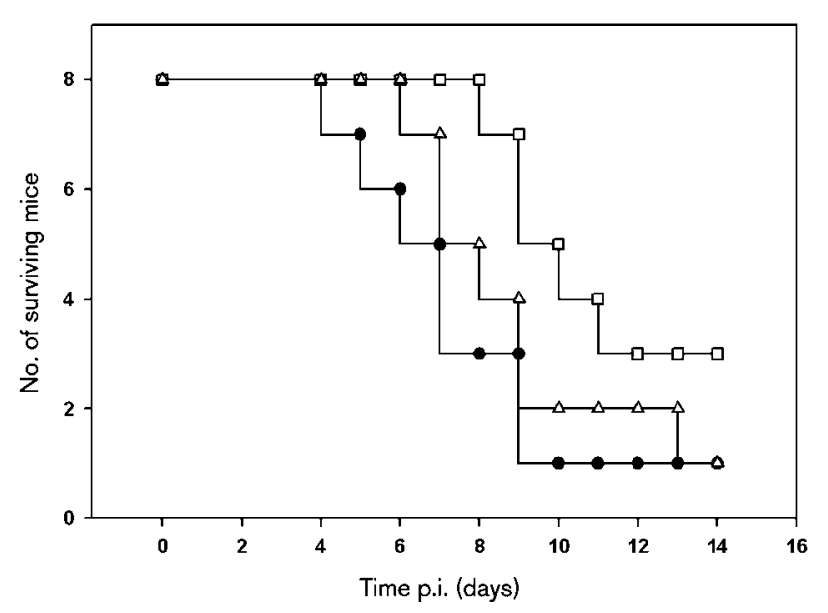

Fig. 4. Mouse virulence study of $S$. Typhimurium strains. BALB/c mice were orally infected with $10^{6}$ c.f.u. of $S$. Typhimurium wildtype SL1344 (@), the opg $\mathrm{GH}$ mutant strain $(\square)$ or opgGH(pBK16) $(\triangle)$. Cells were suspended in $0.2 \mathrm{ml}$ saline and mortality was determined over a period of 15 days. Lines represent the number of animals surviving in each experimental group over time ( $n=8$ per group). The experiment was repeated three times; survival curves from a representative experiment are shown.

within 10-12 days post-challenge with the wild-type strain SL1344 (data not shown). The $\mathrm{LD}_{50}$ for the opgGH mutant had a substantially higher $\operatorname{LD}_{50}\left(\log _{10} 6.9, P=0.001\right.$ at $10^{5}$ cells per animal), indicating that the strain expressed reduced virulence compared to SL1344. Bacterial colonization of individual organs was examined 6 days after the oral dose of $10^{7}$ cells per animal. Colonization of the intestine, spleen and liver, as measured by c.f.u. (g organ wt $)^{-1}$ was approximately 100 - to 1000 -fold lower for mice receiving the opgGH mutant strain compared to the wildtype parent (Fig. 5).

\section{LPS analysis of opgGH mutant}

Possible involvement of opgGH in the synthesis of other hexosyl-containing polymers prompted us to examine comparatively the expression of LPS in the opgGH mutant with that of parental strain SL1344. Electrophoresis of LPS on SDS-PAGE gels revealed no significant differences between wild-type SL1344 and the opgGH mutant (data not shown). Silver-staining of the gel showed that the LPS from all of the strains fractionated into approximately 25 bands.

\section{OPGs and stress-tolerance phenotypes}

The methods used to analyse stress-tolerance phenotypes are described in supplementary data, available with the online version of this paper. The ability to withstand acid and alkali stress was examined by exposing cells to extreme $\mathrm{pH}\left(\mathrm{pH} 3.0\right.$ and 9.8) for $3 \mathrm{~h}$ at $37^{\circ} \mathrm{C}$ (Fig. S2a, available with the online version of this paper). Although acid-shock

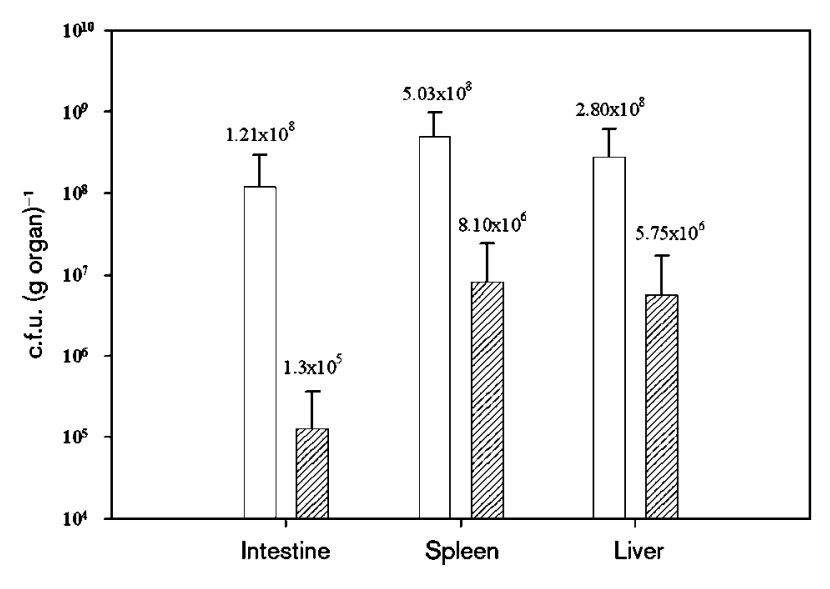

Fig. 5. Effect of the opgGH mutation on tissue colonization. Groups of five mice were infected orally with $S$. Typhimurium wildtype strain SL1344 (open bars) or the mutant strain SG111 (shaded bars), each at $1.5 \times 10^{7}$ organisms per mouse. The number of bacteria present in different organs was determined 6 days after infection. Each bar represents the mean for five mice; error bars are SEM. Data shown are representative of three independent experiments. $P<0.0001$ for all tissues.

of $\mathrm{pH} 3.0$ generated a 3-log reduction, there was no significant difference between the mutant and wild-type strain, and $0.1 \%$ of the original cell population survived in both strains. Alkaline stress conditions resulted in only a 1log reduction in both the wild-type and the opgGH mutant strain. Likewise, no differences were observed in opgGH mutant of strain FIRN in comparison with the wild-type parental strain (data not shown). Further analysis of additional stress conditions, such as exposure to heat shock $\left(5 \mathrm{~min}\right.$ at $\left.58{ }^{\circ} \mathrm{C}\right)$, bile salts $\left(24 \mathrm{~h}\right.$ in $15 \%$ ox bile at $\left.37{ }^{\circ} \mathrm{C}\right)$, polymyxin $\left(1 \mu \mathrm{g} \mathrm{ml} \mathrm{g}^{-1}\right.$ for $1 \mathrm{~h}$ at $\left.37^{\circ} \mathrm{C}\right)$, and oxidative stress $\left(20 \mathrm{mM}\right.$ hydrogen peroxide for $2 \mathrm{~h}$ at $37^{\circ} \mathrm{C}$ ) resulted in no discernible differences between wild-type and the opgGH mutant strain (Fig. S2a). Lastly, exposure to detergent ( $5 \%$ SDS, w/,v in LB broth) in liquid cultures generated identical growth patterns over $24 \mathrm{~h}$ in shake cultures $\left(37{ }^{\circ} \mathrm{C}, 220\right.$ r.p.m.) (Fig. S2b). There were no apparent differences in the colony morphology of the wildtype and the mutant strain.

\section{Phenotypic microarray analysis}

The methods used for phenotypic microarray analysis are described in supplementary data, available with the online version of this paper. Based on tetrazolium redox chemistry that produces a colour change in response to cell growth and respiration (Bochner, 2003; Zhou et al., 2003), high-throughput analysis of ionic and $\mathrm{pH}$ tolerance was studied. In three independent experiments where the opgGH mutant strain was compared with the parental wildtype strain for $72 \mathrm{~h}$, the mutant strain had a long lag period in acidic growth medium ( $\mathrm{pH}$ 5.0) (Fig. S3, available with the online version of this paper). Phenotypic microarray 
analysis showed that, comparatively, wild-type SL1344 cells under growth conditions of $\mathrm{pH} 4.5$ could utilize various amino acids such as proline, threonine and aspartic acid more efficiently to alter the growth medium $\mathrm{pH}$ than could the opgGH mutant. The differences in the dye reduction (measured as area units; Fig. S3) between SL1344 and SG111 for some amino acids, was greater than twofold (i.e. arginine, asparagine and proline). We followed the highthroughput observation of extended lag under acidic growth conditions by performing individual tests and monitored viable cell counts. There was no discernible difference in the growth patterns of the two strains when growth was monitored by viable cell numbers (data not shown), but there was a significant difference in cellular ATP content in the two strains. At pH 5.0, the mutant strain had lower ATP levels after 12, 15 and $18 \mathrm{~h}$ incubation (Table 2). The differences in ATP levels were less prominent after $24 \mathrm{~h}$ incubation in acidic growth medium, and both strains had comparable levels of ATP. No differences in ATP content were observed at $\mathrm{pH} 5.5$ and above (data not shown).

\section{DISCUSSION}

In this study, we have described the isolation and compositional analysis of OPGs from $S$. Typhimurium SL1344. Mutagenesis of the opgGH operon resulted in the total loss of OPG biosynthesis, and the mutant strain, SG111, was less virulent in mice. Many factors are involved in the virulence of pathogenic bacteria, and OPGs appear to be among them. In comparison with the wild-type strain, the opgGH mutant had lower ATP levels during growth initiation in low-pH medium. Biolog-based analysis of cell phenotypes is based on measuring overall cellular metabolic rates, resulting in a change in the redox potential which is monitored by a dye (Bochner et al.,

Table 2. ATP content of $S$. enterica serovar Typhimurium strains SL1344 and SG111

ATP levels were monitored by luminescence enzyme assay and measured as relative light units (RLU). The RLU (luminescence) data were converted to mol ATP (using a standard ATP reference curve) and normalized for viable cell count (c.f.u.). Mean values $(n=3)$ in each row that are not followed by the same letter in parenthesis indicate significant $(P<0.05)$ differences.

\begin{tabular}{|c|c|c|}
\hline \multirow{2}{*}{ 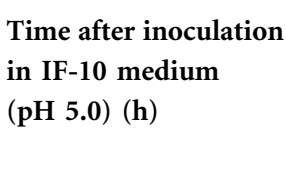 } & \multicolumn{2}{|c|}{$10^{18} \times$ ATP content $\left(\mathrm{mol}\right.$ c.f.u. $\left.{ }^{-1}\right)$} \\
\hline & SL1344 & SG111 \\
\hline 12 & $1.01 \pm 0.04(\mathrm{a})$ & $0.31 \pm 0.01(\mathrm{~b})$ \\
\hline 15 & $0.6 \pm 0.02(a)$ & $0.25 \pm 0.03(b)$ \\
\hline 18 & $0.43 \pm 0.01$ (a) & $0.30 \pm 0.01(b)$ \\
\hline 24 & $0.37 \pm 0.02$ (a) & $0.36 \pm 0.03$ \\
\hline
\end{tabular}

2001). In light of an apparent paradoxical situation where viable cell numbers could not corroborate high throughput Biolog data (which indicated lower growth potential for the opgGH mutant), we examined cellular ATP contents of cells grown under acidic conditions ( $\mathrm{pH}$ 5.0). The observation that the opgGH mutant had lower ATP levels compared to the wild-type cells (Table 2) may suggest that the mutant may be more susceptible to antimicrobial peptides in a low-pH environment, which occurs in phagosomes, and may result in reduced virulence (Alpuche Aranda et al., 1992; Rathman et al., 1996). An increase in $\mathrm{LD}_{50}$ for the opgGH mutant (Fig. 4) and poor recovery of this strain in mouse intestine (Fig. 5) could indicate that fewer bacteria survive oral inoculation or the increased ability of the host to kill the opgGH mutant. In addition, we observed reduced cellular respiration (Biologbased dye reduction) when the opgGH mutant was exposed to $\mathrm{pH} 4.5$ in the presence of proline, threonine and aspartic acid (Table S1 and Fig. S3). Amino acid decarboxylase systems are known to protect enteric pathogens from gastric acidity (Bearson et al., 1997; Bhagwat et al., 2005; Foster, 2004). In this context, growth and respiration at low $\mathrm{pH}$ in the presence of different amino acid pools mimicking the conditions of phagosomes needs to be examined (Alpuche Aranda et al., 1992; Rathman et al., 1996).

Several studies have been conducted to elucidate the function of OPGs in Gram-negative bacteria, and a number of distinctive features specific to Salmonella sp. have emerged from the present study. For example, opgGH mutants of Erwinia chrysanthemi showed increased capsular polysaccharide synthesis (giving rise to mucoid colonies) as well as hypersensitivity towards bile salts (Cogez et al., 2001; Page et al., 2001). No change in colony morphology or change in sensitivity towards bile salts was observed for strain SG111 (Fig S1a). OPG synthesis in Brucella sp., which are nonmotile, is not under osmotic control, but a defect in the opgG gene results in increased sensitivity to surfactants (SDS and deoxycholic acid) (Arellano-Reynoso et al., 2005; Briones et al., 2001), indicating cell-surface alterations, a phenotype also not observed in strain SG111 (Fig S2b). The other significant component of Gram-negative bacteria, the enterobacterial common antigen, has been proposed to play an important role in virulence by protecting the pathogen from bile salts (Ramos-Morales et al., 2003). Nonetheless, the data showing that bile salt resistance of the opgGH mutant strain was comparable to the wild-type strain (Fig. S2a), coupled with the fact that the lipopolysaccharide gel pattern was unchanged (data not shown), may indicate that there may be no major alterations in this cell envelope component in the opgGH mutant. Stress-tolerance studies involving oxidative stress, $\mathrm{pH}$, starvation, bile salts and heat challenge were unable to distinguish between survival responses of the wild-type and $o p g G H$ mutant strains (Fig. S2a).

Despite leading to exceedingly different outcomes in symbiotic and pathogenic interactions with their respective eukaryotic hosts, the possible involvement of OPGs in the 
respective interactions of many bacteria shows striking parallels (Arellano-Reynoso et al., 2005; Galan \& Cossart, 2005; LeVier et al., 2000). For example, the $h r p M$ mutant of Pseudomonas syringae pv. syringae does not synthesize OPGs and loses its ability to cause brown spot disorder on common bean (Phaseolus vulgaris) (Loubens et al., 1993). $P$. aeruginosa contains gene homologues for linear and cyclic OPGs (Stover et al., 2000) and it has been shown that transcripts for (cyclic) OPG synthesis are stimulated in $P$. aeruginosa cells grown in biofilms (Mah et al., 2003). Although a mutation in an $n d v B$-like gene (Bhagwat \& Keister, 1995) enabled cells to form biofilms with the characteristic wild-type architecture, it did not result in the development of high-level biofilm-specific antibiotic resistance. It has been further demonstrated that cyclic OPGs protect the cells by sequestering antibiotics and thereby increase survival of the pathogen inside the host. On the other hand, linear OPGs of $P$. aeruginosa are encoded by $o p g G H$ and it appears that this locus is not involved in the resistance of biofilms to antibiotics (Lequette et al., 2007). Further studies will be needed to define the precise role played by linear OPGs of $S$. Typhimurium in the mouse virulence model.

\section{ACKNOWLEDGEMENTS}

We thank Dr Brian Vinyard, Biometric Consulting Section, USDAARS, Beltsville, MD, USA, for his help in statistical analysis. The study was supported in part by the China Scholarship Council, Ministry of Education, China (L.L.) and the overseas Industrial Attachment Program of the School of Life Sciences and Chemical Technology, Ngee Ann Polytechnic, Singapore (B. P.).

\section{REFERENCES}

Alpuche Aranda, C. M., Swanson, J. A., Loomis, W. P. \& Miller, S. I. (1992). Salmonella typhimurium activates virulence gene transcription within acidified macrophage phagosomes. Proc Natl Acad Sci U S A 89, 10079-10083.

Arellano-Reynoso, B., Lapaque, N., Salcedo, S., Briones, G., Ciocchini, A. E., Ugalde, R. A., Moreno, E., Moriyon, I. \& Gorvel, J. (2005). Cyclic $\beta$-1,2-glucan is a Brucella virulence factor required for intracellular survival. Nat Immunol 6, 618-625.

Bearson, S., Bearson, B. \& Foster, J. W. (1997). Acid stress responses in enterobacteria. FEMS Microbiol Lett 147, 173-180.

Bhagwat, A. A. \& Keister, D. L. (1995). Site-directed mutagenesis of the $\beta(1,3)$-(1,6)-glucan synthesis locus of Bradyrhizobium japonicum. Mol Plant Microbe Interact 8, 366-370.

Bhagwat, A. A., Gross, K. C., Tully, R. E. \& Keister, D. L. (1996). $\beta$ Glucan synthesis in Bradyrhizobium japonicum: Characterization of a new locus $(n d v C)$ influencing $\beta$-(1,6)-linkages. J Bacteriol 178, 46354642.

Bhagwat, A. A., Mithöfer, A., Pfeffe, P. E., Kraus, C., Ebel, J. \& Keister, D. L. (1999). Further studies on the role of cyclic $\beta$-glucans in symbiosis. A $n d v C$ mutant of $B$. japonicum synthesizes cyclodekais(1,3)- $\beta$-glucosyl. Plant Physiol 119, 1057-1064.

Bhagwat, A. A., Chan, L., Han, R., Tan, J., Kothary, M., Jean-Gilles, J. \& Tall, B. D. (2005). Characterization of enterohemorrhagic Escherichia coli strains based on acid resistance phenotypes. Infect Immun 73, 4993-5003.

Bochner, B. R. (2003). New technologies to assess genotypephenotype relationships. Nat Rev Genet 4, 309-314.

Bochner, B. R., Gadzinski, P. \& Panomitros, E. (2001). Phenotype microarrays for high-throughput phenotypic testing and assay of gene function. Genome Res 11, 1246-1255.

Bohin, J.-P. \& Lacroix, J.-M. (2007). Osmoregulation in the periplasm. In The Periplasm, pp. 325-341. Edited by M. Ehrmann. Washington, DC: American Society for Microbiology.

Briones, G., Inon de lannino, N., Steinberg, M. \& Ugalde, R. (1997). Periplasmic cyclic 1,2- $\beta$-glucan in Brucella spp. is not osmoregulated. Microbiology 143, 1115-1124.

Briones, G., Iannino, I., Roset, M. S., Vigliocco, A., Paulo, P. S. \& Ugalde, R. A. (2001). Brucella abortus cyclic $\beta$-1,2-glucan mutants have reduced virulence in mice and are defective in intracellular replication in HeLa cells. Infect Immun 69, 4528-4535.

Chen, R., Bhagwat, A. A. \& Keister, D. L. (2003). A motility revertant of the $n d v B$ mutation in Bradyrhizobium japonicum. Curr Microbiol 47, 431-433.

Coburn, B., Li, Y., Owen, D., Vallance, B. A. \& Finlay, B. B. (2005). Salmonella enterica serovar Typhimurium pathogenicity island 2 is necessary for complete virulence in a mouse model of infectious enterocolitis. Infect Immun 73, 3219-3227.

Cogez, V., Talaga, P., Lemoine, J. \& Bohin, A. (2001). Osmoregulated periplasmic glucans of Erwinia chrysanthemi. J Bacteriol 183, 31273133.

Dubois, M., Gilles, K. A., Hamilton, J. K., Rebers, P. A. \& Smith, F. (1956). Colorimetric method for determination of sugars and related substances. Anal Biochem 28, 350-356.

Fiedler, W. \& Rotering, H. (1988). Properties of Escherichia coli mutants lacking membrane-derived oligosaccharides. J Biol Chem 263, 14684-14689.

Finney, D. J. (1971). Probit Analysis, 3rd edn. London: Cambridge University Press.

Foster, J. W. (2004). Escherichia coli acid resistance: tales of an amateur acidophile. Nat Rev Microbiol 2, 898-907.

Galan, J. E. \& Cossart, P. (2005). Host-pathogen interactions: a diversity of themes, a variety of molecular machines. Curr Opin Microbiol 8, 1-3.

Hanoulle, X., Rollet, E., Clantin, B., Landrieu, l., Odberg-Ferragut, C., Lippens, G., Bohin, J.-P. \& Villeret, V. (2004). Structural analysis of Escherichia coli OpgG, a protein required for the biosynthesis of osmoregulated periplasmic glucans. J Mol Biol 342, 195-205.

Hoiseth, S. K. \& Stocker, B. A. (1981). Aromatic-dependent Salmonella typhimurium are non-virulent and effective as live vaccines. Nature 291, 238-239.

Hubert, J. J., Bohidar, N. R. \& Peace, K. E. (1988). Assessment of pharmacological activity. In Biopharmaceutical Statistics for Drug Development. Edited by K. E. Peace. New York: Marcel Dekker.

Johnson, K. G. \& Perry, M. B. (1976). Improved techniques for the preparation of bacterial lipopolysaccharides. Can J Microbiol 22, 2934.

Kennedy, E. P. (1996). Membrane-derived oligosaccharides (periplasmic $\beta$-D-glucans) of Escherichia coli. In Escherichia coli and Salmonella Cellular and Molecular Biology, pp. 1064-1074. Edited by F. C. Neidhardt \& others. Washington, DC: American Society for Microbiology.

Kennedy, E. P., Rumley, M. K., Schulman, H. \& Van Golde, L. M. (1976). Identification of $s n$-glycerol-1-phosphate and phsophoetha- 
nolamine residues linked to the membrane-derived oligosaccharides in Escherichia coli. J Biol Chem 251, 4208-4213.

Kim, K. S., Rao, N. N., Fraley, C. D. \& Kornberg, A. (2002). Inorganic polyphosphate is essential for long-term survival and virulence in Shigella and Salmonella spp. Proc Natl Acad Sci U S A 99, 7675-7680.

Lacroix, J., Lanfroy, E., Cogez, V., Lequette, Y., Bohin, A. \& Bohin, J.-P. (1999). The $m d o C$ gene of Escherichia coli encodes a membrane protein that is required for succinylation of osmoregulated periplasmic glucans. J Bacteriol 181, 3626-3631.

Lequette, Y., Odberg-Ferragut, C., Bohin, J.-P. \& Lacroix, J. (2004). Identification of $m d o D$, an $m d o G$ paralog which encodes a twinarginine-dependent periplasmic protein that controls osmoregulated periplasmic glucan backbone structures. J Bacteriol 186, 3695-3702.

Lequette, Y., Rollet, E., Delangle, A., Greenberg, E. P. \& Bohin, J.-P. (2007). Linear osmoregulated periplasmic glucans are encoded by the opgGH locus of Pseudomonas aeruginosa. Microbiology 153, 32553263.

LeVier, K., Phillips, R. W., Grippe, V. K., Roop, R. M., II \& Walker, G. C. (2000). Similar requirements of a plant symbiont and a mammalian pathogen for prolonged intracellular survival. Science 287, 2492-2493.

Lin, J., Lee, I. S., Frey, J., Slonczewski, J. L. \& Foster, J. W. (1995). Comparative analysis of extreme acid survival in Salmonella typhimurium, Shigella flexneri, and Escherichia coli. J Bacteriol 177, 4097-4104.

Loubens, I., Debarbieux, L., Bohin, A., Lacroix, J. \& Bohin, J.-P. (1993). Homology between a genetic locus $(m d o A)$ involved in the osmoregulated biosynthesis of periplasmic glucans in Escherichia coli and a genetic locus ( $h r p M)$ controlling the pathogenicity of Pseudomonas syringae. Mol Microbiol 10, 329-340.

Mah, T. F., Pitts, B., Pellock, B., Walker, G. C., Stewart, P. S. \& O'Toole, G. A. (2003). A genetic basis for Pseudomonas aeruginosa biofilm antibiotic resistance. Nature 426, 306-310.

Merkle, R. K. \& Poppe, I. (1994). Carbohydrate composition analysis of glycoconjugates by gas-liquid chromatography/mass spectrometry. Methods Enzymol 230, 1-15.

Page, F., Altabe, S., Hugouvieux-Cotte-Pattat, N., Lacroix, J., RobertBaidouy, J. \& Bohin, J.-P. (2001). Osmoregulated periplasmic glucan synthesis is required for Erwinia chrysanthemi pathogenicity. J Bacteriol 183, 3134-3141.

Parkhill, J., Dougan, G., James, K. D., Thomson, N. R., Pickard, D., Wain, J., Churcher, C., Mungall, K. L., Bentley, S. D. \& other authors (2001). Complete genome sequence of a multiple drug resistant Salmonella enterica serovar Typhi CT18. Nature 413, 848-852.

Ramos-Morales, F., Prieto, A. I., Beuzon, C. R., Holden, D. W. \& Casadesus, J. (2003). Role for Salmonella enterica enterobacterial common antigen in bile resistance and virulence. J Bacteriol 185, 5328-5332.

Rathman, M., Sjaastad, M. \& Falkow, S. (1996). Acidification of phagosomes containing Salmonella typhimurium in murine macrophages. Infect Immun 64, 2765-2773.

SAS Institute (1999). SAS/STAT User's Guide version 8. The PROBIT Procedure, pp. 2831-2872. Cary, NC: SAS Institute.

Sprott, G. D., Koval, S. F. \& Schnaitman, C. A. (1994). Cell fractionation. In Methods for General and Molecular Bacteriology, pp. 72-103. Edited by P. Gerhardt, R. G. E. Murray, W. A. Wood \& N. R. Krieg. Washington, DC: American Society for Microbiology.

Stover, C. K., Pham, X. Q., Erwin, A. L., Mizoguchi, S. D., Warrener, P., Hickey, M. J., Brinkman, F. S., Hufnagle, W. O., Kowalik, D. J. \& other authors (2000). Complete genome sequence of Pseudomonas aeruginosa PAO1, an opportunistic pathogen. Nature 406, 959-964.

Tsai, C. M. \& Frasch, C. E. (1982). A sensitive silver stain for detecting lipopolysaccharides in polyacrylamide gels. Anal Biochem 119, 115119.

Weissborn, A. C., Rumley, M. K. \& Kennedy, E. P. (1992). Isolation and characterization of Escherichia coli mutants blocked in production of membrane-derived oligosaccharides. J Bacteriol 174, 48564859.

York, W. S., Darvill, A. G., McNeil, M., Stevenson, T. T. \& Albersheim, P. (1985). Isolation and characterization of plant cell walls and cell wall components. Methods Enzymol 118, 3-40.

Zhou, L., Xiang-He, L., Bochner, B. R. \& Wanner, B. L. (2003). Phenotype microarray analysis of Escherichia coli K-12 mutants with deletions of all two-component systems. J Bacteriol 185, 4956-4972.

Edited by: D. L. Gally 